\title{
Therapeutic elements in a self-management approach: experiences from group participation among people suffering from chronic pain
}

This article was published in the following Dove Press journal:

Patient Preference and Adherence

16 August 2014

Number of times this article has been viewed

\author{
Bodil Furnes' \\ Gerd Karin Natvig',2 \\ Elin Dysvik'
}

'Department of Health Studies, Faculty of Social Sciences, University of Stavanger, Stavanger, Norway; ${ }^{2}$ Department of Global Public Health and Primary Care, Faculty of Medicine and Dentistry, University of Bergen, Bergen, Norway
Correspondence: Bodil Furnes Department of Health Studies, Faculty of Social Sciences, University of Stavanger, $\mathrm{N}$-4036 Stavanger, Norway

Tel +47518341000

Fax +4751831550

Email bodil.furnes@uis.no
Objective: Chronic pain is a complex, multifaceted subjective experience that involves the whole person. Self-management is the dynamic and continuous process of adapting one's situation to the cognitive, behavioral, and emotional responses necessary to maintain a satisfactory quality of life. Approaches based on cognitive behavioral therapy (CBT) are described as appropriate in assisting people suffering from chronic pain because they challenge maladaptive beliefs and behaviors in relation to pain. This study aimed to explore patients' experiences of therapeutic elements from group participation in a chronic pain management program.

Methods: A qualitative research design with a phenomenological hermeneutic approach was used. Six months after participation in the 8-week course, 34 participants formulated and submitted written reports based on open-ended questions related to their group participation and selfhelp achievement. These reports were analyzed by elements of qualitative content analysis.

Results: The analysis resulted in two subthemes: "The significance of active involvement in gaining new insight" and "The significance of community and group support." These were abstracted in the main theme: "Successful self-management is related to several significant contributions in the group."

Conclusion: An active role with writing, self-revelation, and exchanges of thoughts and feelings in the group seemed to be the key tools for success. In addition, group support and access to other group members' experiences were significant therapeutic elements. We suggest that successful self-management requires knowledge of essential therapeutic elements. In a CBTbased group approach, such elements may offer an important health care contribution.

Keywords: pain management, cognitive behavioral therapy, group therapy, self-directed therapy

\section{Introduction}

Chronic pain is a complex, multifaceted subjective experience that involves not only the body, but also the mind. ${ }^{1,2}$ The pattern of suffering often includes personal stress, psychological disturbances such as depression, and reduced self-esteem. ${ }^{3}$ In addition, chronic pain results in maladaptive and dysfunctional behavior and reduced ability to engage in daily and social activities. Experiencing chronic pain incorporates the individual's thoughts, feelings, and behavior. ${ }^{4}$ Furthermore, the individual's beliefs about their own capabilities can influence their behavior. ${ }^{5}$ Turk $^{4}$ therefore emphasizes that the most appropriate approach in assisting people suffering from chronic pain is to take into account their cognitive, psychosocial, and behavioral factors related to pain. A cognitive behavioral therapy (CBT) approach involves three important aspects of learning: cognitive (information and understanding), affective (attitudes and feelings), and behavior (skills). ${ }^{6}$ Such an approach is based on challenging a 
person's maladaptive beliefs and behaviors about pain, then having them learn adaptive strategies toward becoming an active agent in controlling their own pain. ${ }^{7}$ According to a behavior change approach, people can make real improvements to their health by choosing to change different ways of dealing with life. ${ }^{6}$

According to Barlow et $\mathrm{al}^{8}$ self-management refers to the person's ability to manage symptoms, treatment, physical and psychological consequences, and lifestyle changes related to living with a chronic condition. As such, self-management involves a dynamic and continuous process of adapting one's condition to the cognitive, behavioral, and emotional responses necessary to maintain a satisfactory quality of life. ${ }^{8}$ Within self-management programs, promoting change is essential, and suitable tools are needed. Such programs offer strategies to cope with pain and promote the dignity that comes from the self-management of pain. ${ }^{9}$

Recent findings indicate that people with chronic pain experience decreased abilities to engage in meaningful activities and relationships with others and loss of self-worth, and suggest that processing such losses is an important and challenging task when living with chronic pain. ${ }^{10,11}$ Moreover, support and a sense of community with others in a group are significant for enabling the expression of difficult thoughts and feelings, as well as ways of coping with chronic pain. ${ }^{12}$ As such, group approaches in the treatment of chronic pain can be of great importance as the group may provide a setting in which patients suffering from chronic pain can communicate with others with similar problems and allow them to express their thoughts and feelings regarding their situation. ${ }^{13}$ MacKenzie ${ }^{14}$ and Yalom ${ }^{15}$ highlight self-revelation and learning from others as important supportive elements in a group approach, and call these therapeutic factors. Helping others, group cohesiveness, and interpersonal learning are elements salient to participant improvement during group participation, according to Yalom. ${ }^{15}$ In addition, therapeutic writing can be a tool for expressing individual experiences and improving adaptation to chronic pain. ${ }^{16}$

Assisting chronic pain sufferers to manage their lives is crucial. Successful self-management of a chronic pain situation requires knowledge of the chronic state and skills to maintain psychosocial functioning. ${ }^{8}$ In addition, increased understanding of the sufferer's situation during rehabilitation might offer an additional fundament for health care workers. ${ }^{12}$ Based on these considerations, the aim of this paper is to explore patients' experiences of therapeutic elements from group participation in a chronic pain management program.

\section{Methods}

This study used a qualitative design with a phenomenological hermeneutic approach to explore and interpret the described phenomena related to participating and self-management in a chronic pain management group. Such a qualitative approach can help improve our understanding of the phenomena under study as individual experiences are captured. ${ }^{17}$

\section{Participants and sample}

A consecutive sample of 34 outpatients suffering from chronic pain was recruited for participation in group-based chronic pain management programs. Participants from three programs participated in this study. The study was carried out in a rehabilitation unit of a university hospital. Participants met the following inclusion criteria:

- 18-67 years of age

- Chronic nonmalignant pain lasting for more than 6 months

- Medical investigation and/or treatment completed prior to referral

- Motivation to participate in an active rehabilitation program, and

- No ongoing litigation related to the cause of their pain. Participants' mean age was 49 years. They suffered from pain resulting from different problems afflicting different body regions or generalized pain. Twenty-one participants had suffered from pain for more than 6 years.

Prior to enrolment in the program, all patients had a medical evaluation. They were fully informed about the program, including expectations and obligations. In addition, written instructions were distributed. It was emphasized that participation was voluntary and that participants could leave the program at any time. Confidentiality was guaranteed and a written consent form was obtained at recruitment. The study was approved by the Regional Ethics Committee and the Data Inspectorate (ethical approval no. 428.10).

\section{The chronic pain management program}

The 8-week group-based chronic pain management program was built on CBT and consisted of weekly group meetings with supervised dialogue, expressive writing, physical activity, education, and corresponding homework for which writing tasks were included (Table 1). The groups were 
Table I The chronic pain management program: organization of the sessions and corresponding topics covered in the program

\begin{tabular}{|c|c|c|c|}
\hline Session & Physical activity & Topics & Homework/writing \\
\hline I & & $\begin{array}{l}\text { Establishing the } \\
\text { group goals }\end{array}$ & Develop own goals/present life situation, hope and joy ${ }^{a}$ \\
\hline 2 & Progressive relaxation & $\begin{array}{l}\text { Physical activity and } \\
\text { pain }\end{array}$ & Plan for physical activity \\
\hline 3 & Progressive relaxation & $\begin{array}{l}\text { Pain as a complex } \\
\text { phenomenon }\end{array}$ & $\begin{array}{l}\text { Record factors that increase and decrease pain/the pain problem, } \\
\text { thoughts and feelings related to loss and grief }\end{array}$ \\
\hline 4 & Breathing, movements & $\begin{array}{l}\text { Muscle tension, } \\
\text { relaxation, and pain }\end{array}$ & Muscle relaxation and tension; practice in autogenic training \\
\hline 5 & Active exercise training & Coping and pain & $\begin{array}{l}\text { Record coping strategies and appraisals, and alternative ways of } \\
\text { coping/previous and present relationship with important persons }{ }^{a}\end{array}$ \\
\hline 6 & Mobility, stability & $\begin{array}{l}\text { Self-esteem, social } \\
\text { network, and pain }\end{array}$ & $\begin{array}{l}\text { Record self-esteem and social network, and alternative ways of } \\
\text { behaving }\end{array}$ \\
\hline 7 & Mobility, stability & $\begin{array}{l}\text { Thoughts, feelings, } \\
\text { and behaviors }\end{array}$ & $\begin{array}{l}\text { Record thinking patterns and the relationship between thoughts, } \\
\text { feelings and behaviors/adaptation, a meaningful life, future plans }{ }^{\mathrm{a}}\end{array}$ \\
\hline 8 & Active exercise training & $\begin{array}{l}\text { Communication, } \\
\text { self-help }\end{array}$ & $\begin{array}{l}\text { Record of communication patterns and suggestions for } \\
\text { improvement }^{\mathrm{a}}\end{array}$ \\
\hline
\end{tabular}

Note: ${ }^{T}$ Topics for expressive writing.

led by one nurse counselor and a volunteer chronic pain sufferer who had completed the program and been trained in counseling.

\section{Data collection}

Six months after participation in the 8-week program, participants formulated and submitted written reports based on open-ended questions relating to their group participation and achievement of self-help. The reports provided subjective descriptions about the significance of the course, the participants' experiences of change, and their chronic pain situation.

\section{Analysis}

Transcribed reports were analyzed using elements of qualitative content analysis. ${ }^{18,19}$ The analytical process occurred in six stages: 1) transcription of the reports; 2) open, independent reading of all material to gain an overall impression of the text; 3 ) identification of meaning units; 4) categorization; 5) abstraction in subthemes and themes; and 6) reflection and discussion (Tables 2 and 3).

\section{Results}

The analyses resulted in two subthemes:

- The significance of active involvement in gaining new insight

- The significance of community and group support.

These subthemes were abstracted in one main theme: "Successful self-management is related to several significant contributions in the group." The themes illustrate the latent content of the participants' reports. ${ }^{18}$
Quotations from the reports were selected as those that best convey the authenticity of the participants' experiences. The quotations illustrate typical aspects of the subthemes abstracted from the categories. The two subthemes form the subheadings in the following presentation of the findings.

Surprisingly, the empirical material of this study appears mostly homogeneous. All of the participants reported that it had been of great importance to them to join the group and all emphasized that they had gained acknowledgment and new insights from the experience.

\section{The significance of active involvement in gaining new insight}

Sharing experiences related to living with chronic pain meant that the participants became more aware of how they were able to influence their situation. Several participants emphasized that learning positive ways of thinking was crucial, and that breaking negative thought patterns required active awareness. One of the participants said:

It is hard work to try to release positive thoughts, but I am working on this all the time. I got many pieces of advice from other group members; one was 'keep telling yourself positive things'. I have become focused on opportunities that make me carry on despite the pain. $(\mathrm{J})$

Participants found it interesting to listen to others' experiences, and found the feedback from others to be valuable. The significance of active involvement in discussions and reflections in the group was emphasized, and input from the group was described as useful in different ways: 
Table 2 Stages of the analytic process

\begin{tabular}{|c|c|}
\hline I. Transcription & Data were transcribed \\
\hline $\begin{array}{l}\text { 2. Open independent } \\
\text { reading }\end{array}$ & $\begin{array}{l}\text { All reports were carefully and independently read by two of the authors (BF, ED) and discussed to } \\
\text { gain an overall impression of the participants' experiences }\end{array}$ \\
\hline $\begin{array}{l}\text { 3. Identification of } \\
\text { meaning units }\end{array}$ & Patterns in the data were identified by dividing the text into meaning units \\
\hline 4. Categorization & $\begin{array}{l}\text { Important nuances were discovered by searching for common and distinctive features and variations, } \\
\text { and agreeing on suitable categories to secure reliability and validity }\end{array}$ \\
\hline 5. Abstraction in & Two subthemes were formulated \\
\hline subthemes and themes & An analytic reflection and abstraction were then performed by searching for an overall theme (BF, ED) \\
\hline $\begin{array}{l}\text { 6. Reflection and } \\
\text { discussion }\end{array}$ & $\begin{array}{l}\text { Discussion among all authors (BF, ED, GKN) focused on relevant theory to illuminate and deepen } \\
\text { understanding of the findings }\end{array}$ \\
\hline
\end{tabular}

Others with similar experiences were of great help. The group members often suggested several ways of handling different problems. Hearing their stories about handling the situation was thought provoking. $(\mathrm{P})$

I got much advice. For example, that increased physical activities can improve my situation. I learned to focus on possibilities and not limitations. (A)

One person told us that changes lie in how we deal with pain. I exercise more and am more social. (K)

The use of writing as a processing tool was described as tough but rewarding work. Being asked to write down their thoughts and feelings led participants to reflect on different situations and enabled them to identify problem areas in their life. The writing tasks led to new thoughts, and dialogue in the group was a great supplement. Some of the participants concluded:

The writing was awareness raising. It brought up several thoughts and resulted in new perspectives. $(\mathrm{H})$

After you had written it down, you gained a new focus, you shared (it) with others, and you got advice and guidance. (M)

Several of the participants pointed to the importance of self-help and taking an active role in their own pain situation, but this was characterized as hard work. Participants' awareness of difficult thoughts and feelings and expression of loss and grief experiences was a step toward changing their attitudes in dealing with pain. Active participation in the group and writing tasks meant opportunities for new understanding and altered behavior relating to their chronic pain situation.

\section{The significance of community and group support}

The exchange of experiences in the group raised awareness of participants' pain situations, and gave access to the reflections of others and more adaptive choices. Furthermore, the other participants represented hope and endurance by focusing on proposed solutions and corrections. All the participants identified fellowship, understanding, and trust as important in creating an inclusive group atmosphere where they could share their life stories, thoughts, and feelings. Through sharing, they discovered that others had similar problems, and this created fellowship, understanding, and acceptance. When sharing their problems, common experiences became clear:

We had a common destiny and this was a sort of common comfort. I recognized myself in everything he said! Everything! (G)

Participants emphasized that they felt safe and free to talk and that they were therefore able to exchange burdensome experiences. A feeling of community was described as fundamental for confidence and safety. Participants described how the group was a unique place to open up about their concerns:

The group is a safe place where I can just be me. The other members understand me. We recognize ourselves in the other. (B)

I could share everything with the others in the group.

They were fabulous, caring people to me. (D)

Positive beliefs and choices were also a focus, and the majority of participants underlined the importance of these announcements as powerful inputs. They described that they were highly encouraged in the group and that energy and hope were mobilized.

Several participants emphasized that the group leaders created a safe climate and that they were accepted as a unique person. Such elements were described as being crucial for openness and their willingness to share their own thoughts and feelings in the group. Difficult situations were discussed among the participants and feedback from the supervisors 
Table 3 Examples of qualitative content analysis $(\mathrm{N}=34)$

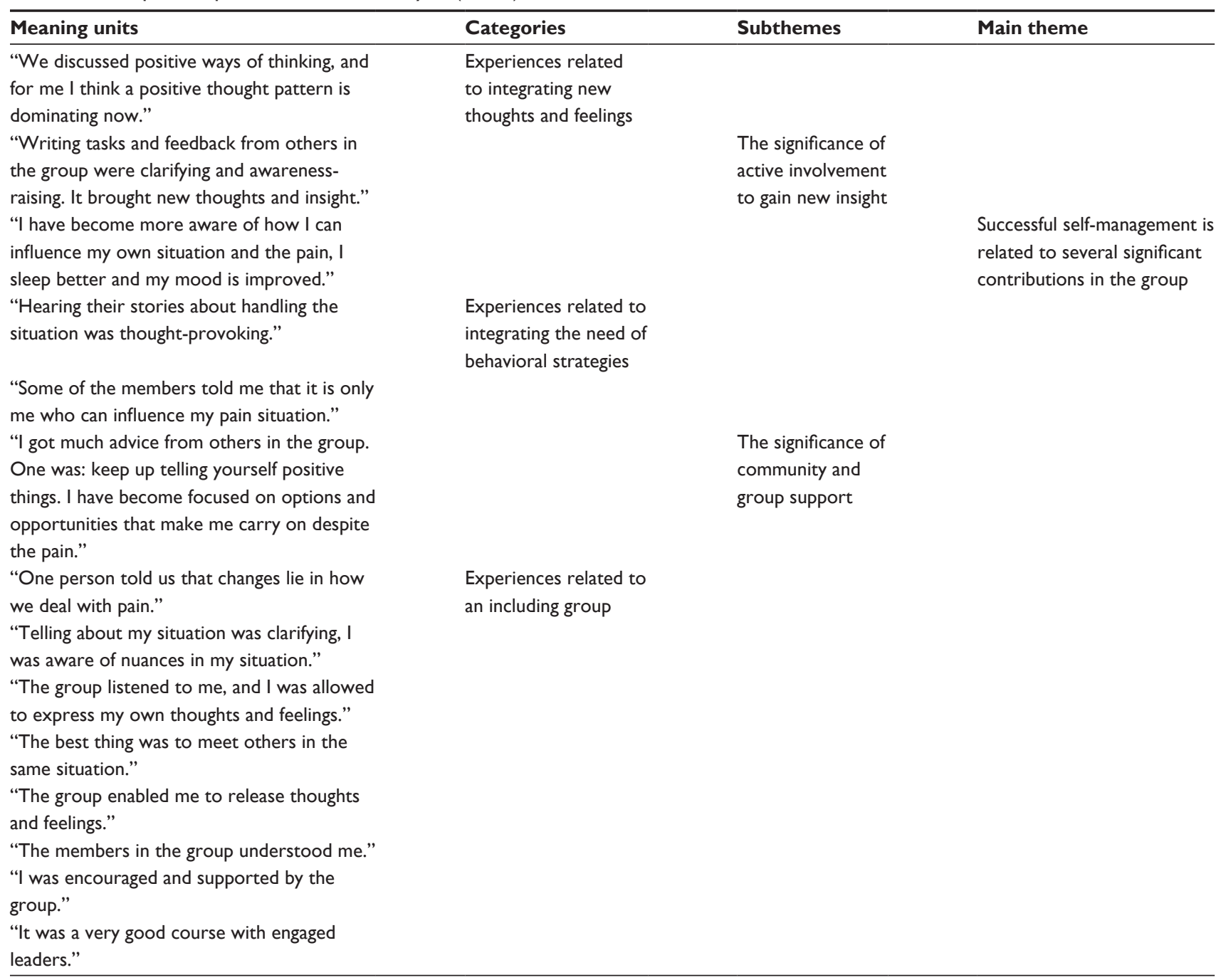

and the members in the group was described as important for assessing their own capabilities.

\section{Discussion}

The aim of the current paper is to explore the experiences of therapeutic elements from group participation in a chronic pain management program. The discussion is based on the main theme: "Successful self-management is related to several significant contributions in the group." The discussion is structured on the basis of what we interpret and describe as important therapeutic elements. In the Discussion section, theory can highlight the meaning of our findings.

\section{Active role and increased insight}

The results of the present study show that active involvement in the group provided opportunities to open up and to exchange thoughts and feelings. In addition, we found that most of the participants emphasized that they gained increased insight as a result of having access to other members' experiences, reflections and advice. MacKenzie ${ }^{14}$ emphasizes that self-disclosure is at the heart of group participation because it is essential for identifying problems and learning from each other. This can help patients gain a better understanding of pain and influencing factors, and patients can be taught effective coping skills. ${ }^{13}$

The results clearly point to the fact that several participants became aware that change depended on their own efforts and having an active role. Our group management program was based on a CBT approach, which focuses on self-management: the persons' ability to help themselves and modify their own thoughts, feelings, and behaviors. ${ }^{4}$ A key skill in such approaches is guided discovery, which means that patients are guided to discover things for themselves. ${ }^{20}$ The person's beliefs about their own capabilities do not 
necessarily reflect their "true" capabilities, and it is therefore considered important to enhance the person's positive beliefs and coping abilities. ${ }^{5}$ Miller ${ }^{21}$ indicates several nursing approaches that may be useful for fostering endurance in this group of patients. Among these, establishing relationships, motivation, a coping skills repertoire, and devising and revising goals are described. ${ }^{20}$ The development of such effective helping relationships is crucial in a self-management approach. $^{20}$

The present management program included homework with expressive writing based on specific topics. Among the topics were "achieving positive thoughts" and "handling different losses and grief related to the pain situation". Our findings indicate that such homework supplemented with dialogue in the group seemed to help participants to reflect on their thoughts, feelings, and behavior. An expressive and personal form of writing has great potential as a selfhelp tool. ${ }^{22}$ Writing theory and several findings support the importance of writing as a tool in processing grief and in adapting to new life situations. ${ }^{16,22-24}$ In the present study, increased awareness about one's own pain situation, gaining a new perspective, and acknowledging one's limitations and strengths were described as resulting from the writing tasks and group discussion. It has been stated that writing is a sort of introspective technique of discovery, which leads to increased awareness and clarification. ${ }^{25,26} \mathrm{We}$ mean that these can be seen as important elements in participants' abilities to improve their experienced life situation.

In the present study, several participants clearly described the impact of positive input and advice. Previous research has reported that living with chronic pain is a dynamic learning process that involves a relationship with other group members, help from others, and interpersonal learning. ${ }^{15,27,28}$ These factors foster a go-ahead spirit and may lead to improvement and positive outcomes. ${ }^{15}$ According to Keefe et al $^{13}$ attending self-management group programs can help patients gain a better understanding of pain and influencing factors, and learn effective coping skills. Moreover, successful self-management of living with chronic pain requires knowledge and ways of coping with the chronic pain situation. ${ }^{8} \mathrm{We}$ therefore consider that these elements may represent significant contributions to changes in the management of chronic pain.

\section{Community and group support}

The group provided a setting in which patients who suffered from chronic pain were able to make contact with others with similar problems. Our findings indicate that attending the group implied cohesiveness. Feelings of trust, belonging, and togetherness were clearly described. Yalom ${ }^{15}$ reported universality as one of the therapeutic factors in the group; when other members share similar problems, thoughts, and feelings, this provides a sense of community. In the present study, all the participants indicated that they felt confident and supported and that such experiences contributed to their increased well-being. Such factors represent therapeutic elements in the group, according to Yalom. ${ }^{15}$ Moreover, cohesiveness is seen as a core mechanism in the therapeutic relationship in the group. ${ }^{15,29}$

Several participants in our program stated that they were concerned about the others in the group and tried to offer each other various types of encouragement and advice. We assume that sharing stories, how they felt, and what they needed helped the participants to think differently about their situations and gave them the opportunity to work on their problems. Self-disclosure creates a forum for modeling and learning from each other that can lead to changed behavior. ${ }^{14,15}$ As such, support, relationships, and learning from others are therapeutic factors in groups. ${ }^{14,15}$

In our study, the group was characterized as a safe place for self-revelation and expression of personal problems. Some of the participants described the significance of being seen as they are. The group also represented a trusting environment where participants could disclose information about themselves and find understanding and support from people with shared circumstances. This finding is reinforced by Thorn and Kuhajda, ${ }^{30}$ who state that group involvement may fulfill a supportive function, allowing patients to share their inner selves with others in similar situations.

Suffering from chronic pain may be seen as a state of severe distress associated with events that threaten the intactness of the affected person. ${ }^{31}$ Several participants in our program indicated that input from the group gave them hope, including greater courage to improve their lives. There is a growing consensus that therapeutic relationships may greatly affect patient improvement. ${ }^{32}$ Furthermore, the experience and role of hope is very important in understanding coping processes. ${ }^{33}$ Dufault and Martocchio ${ }^{34}$ define hope as "a multidimensional dynamic life force characterized by a confident yet uncertain expectation of achieving a future good which, to the hoping person, is realistically possible and personally significant". Research indicates that hope can be a strategy that enables the person to appraise the situation as a challenge rather than a threat, and fosters problem-focused or emotional-focused resources. ${ }^{33}$ Our study indicates that the participants' expression of their own thoughts and feelings in the group setting has a supportive and awareness-raising 
role and that optimism and positive thinking in the group may create hope. We suggest this may become the basis for an improved situation.

All the participants in our study experienced support and positive feedback from the group. In addition, participants emphasized the significance of a supportive group leader. Leadership in chronic pain management groups is described as navigating between nursing care and different nursing leadership roles. ${ }^{35} \mathrm{~A}$ trusting relationship is required; without this, patients will resist discussing their difficulties. ${ }^{20}$ The nurse leader provided important tasks in the program to motivate the participants to be actively involved and gain a more positive interpretation of their situation. The importance of this role is supported in several studies. ${ }^{36-38}$ Trained leaders have a key role as the participants are vulnerable and have different levels of insight. ${ }^{39}$ Furthermore, the participants' illness experiences and behaviors lead to different kinds of resistance toward change. ${ }^{13}$ As such, useful input and support from the nurse leader in the group can be seen as important for participants' assessment of their own capability and efforts. Our program profile and the nurse performing the counseling emphasized the participants' active role toward succeeding. The combination of support, acceptance, and acknowledgment seemed to make them receptive to change.

\section{Methodological considerations}

These data represent detailed and extensive descriptions, and clear patterns emerged during the analyses. As Graneheim and Lundman ${ }^{18}$ state, it is not always possible to create mutually exclusive categories when dealing with experiences. Moreover, there is no single correct meaning or universal application of research findings. As such, our approach allows the reader to look for alternative interpretations. The data consist of reports from 34 participants and represent detailed and rich descriptions of the topic under investigation, which contributes to secure trustworthiness. In the research process, reliability and validity are ensured through a detailed analytical process, as exemplified in Table 2. Arguments for the most probable interpretations are established through dialogue. ${ }^{18}$ Transferability of the findings to similar clinical situations may be relevant to other self-management approaches, if the participants' culture and context, data collection, and analyses are taken into account.

\section{Conclusion}

Participation in our self-management program for chronic pain sufferers provided increased insight into how to deal with chronic pain. An active role with writing, self-revelation, and exchanges of thoughts and feelings in the group seemed to be key tools for processing loss and grief and gaining new insight. In addition, group support and access to other group members' experiences were significant therapeutic elements.

We suggest that the successful self-management of chronic pain requires knowledge of essential therapeutic elements. CBT-based group approaches incorporating such elements may offer an important health care contribution to these sufferers. It is also relevant to inform rehabilitation professionals about these elements.

\section{Disclosure}

The authors report no conflicts of interest in this work.

\section{References}

1. Dysvik E. Health-related Quality of Life and Coping in Rehabilitation of People Suffering from Chronic Pain [doctoral thesis]. Bergen, Norway: University of Bergen; 2006.

2. Peterson M, Breivik H. Even a "simple" pain condition such as "tennis elbow" is not only a somatic experience: body and mind are inseparable entities. Scand J Pain. 2013;4(3):153-154.

3. Dworkin SF, Sherman JJ. Relying on objective and subjective measures of chronic pain: guidelines for use and interpretation. In: Turk DC, Melzack R, editors. Handbook of Pain Assessment, Second Edition. New York: Guilford Press; 2001:619-638.

4. Turk DC. A cognitive-behavioural perspective on treatment of chronic pain patients. In: Turk DC, Gatchel RJ, editors. Psychological Approaches to Pain Management: A Practitioner's Handbook, 2nd ed. New York: Guilford Press; 2002:138-158.

5. Marks R, Allegrante JP, Lorig K. A review and synthesis of research evidence for self-efficacy-enhancing interventions for reducing chronic disability: implications for health education practice (part I). Health Promot Pract. 2005;6(1):37-43.

6. Naidoo J, Wills J. Health Promotion. Foundations for Practice, Second Edition. London: Bailliere Tindall; 2000.

7. Van Huet H, Innes E, Whiteford G. Living and doing with chronic pain: narratives of pain program participants. Disabil Rehabil. 2009; 31(24):2031-2040.

8. Barlow J, Wright C, Sheasby J, Turner A, Hainsworth J. Self-management approaches for people with chronic conditions: a review. Patient Educ Couns. 2002;48(2):177-187.

9. Taylor SE. Health Psychology. Los Angeles: McGraw-Hill International Edition; 2006.

10. Dysvik E, Natvig GK, Furnes B. A narrative approach to explore grief experiences and treatment adherence in people with chronic pain after participation in a pain-management program: a 6-year follow-up study. Patient Prefer Adherence. 2013;7:751-759.

11. Haraldseid C, Dysvik E, Furnes B. The experience of loss in patients suffering from chronic pain attending a pain management group based on cognitive-behavioral therapy. Pain Manag Nurs. 2014;15(1):12-21.

12. Dysvik E, Kvaløy JT, Furnes B. A mixed-method study exploring suffering and alleviation in participants attending a chronic pain management programme. J Clin Nurs. 2014;23(5-6):865-876.

13. Keefe FJ, Beaupre PM, Gil KM, Rumble ME, Aspnes AK. Group therapy for patients with chronic pain. In: Turk DC, Gatchel RJ, editors. Psychological Approaches to Pain Management: A Practitioner's Handbook, 2nd ed. New York: Guilford Press; 2002:234-255.

14. MacKenzie KR. Introduction to Time-limited Group Psychotherapy. Washington, DC: American Psychiatric Press; 1990.

15. Yalom ID. The Theory and Practice of Group Psychotherapy. 5th ed. New York: Basic Books; 2005. 
16. Furnes B, Dysvik E. Therapeutic writing and chronic pain: experiences of therapeutic writing in a cognitive behavioural programme for people with chronic pain. J Clin Nurs. 2012;21(23-24):3372-3381.

17. Karlberg I, Hallberg LMR, Sarvimäki A. Introduction and aims of the book Health, Public Health and Research on Public Health. In: Hallberg LRM, editor. Qualitative Methods in Public Health Research. Lund: Studentlitteratur; 2002:13-38.

18. Graneheim UH, Lundman B. Qualitative content analysis in nursing research: concepts, procedures and measures to achieve trustworthiness. Nurse Educ Today. 2004;24(2):105-112.

19. Kvale S, Brinkmann S. Interviews. 2nd ed. Los Angeles: Sage; 2009.

20. Furze G, Donnison J, Lewin RJP. The Clinician's Guide to Chronic Disease Management for Long-term Conditions: A Cognitive-Behavioural Approach. Keswick, England: M\&K Publishing; 2008.

21. Miller JF. Coping with Chronic Illness: Overcoming Powerlessness. 2nd ed. Philadelphia: F.A. Davis; 1992.

22. Pennebaker JW. Theories, therapies, and taxpayers: on the complexities of the expressive writing paradigm. Clin Psychol. 2004;11:138-142.

23. Furnes B. Å skrive sorgen - bearbeidelse av sorg. Prosessorientert skriving i møte med en fenomenologisk språkforståelse. En hermeneutisk fenomenologisk studie av skriving som sorgbearbeidelse hos etterlatte [doctoral thesis]. [Writing the grief - Handling the grief. Processoriented writing meeting a phenomenological language comprehension. A hermeneutic phenomenological study of writing and grief processing.] Bergen, Norway: University of Bergen; 2008. Norwegian.

24. Lowe G. Health-related effects of creative and expressive writing. Health Educ. 2006;106:60-70.

25. Bolton G, Wright JK. Conclusions and looking forward. In: Bolton G, Howlett S, Lago C, Wright JK, McMillan I, editors. Writing Cures: Introductory Handbook of Writing in Counselling and Psychotherapy. New York: Brunner-Routledge; 2004:228-231.

26. Elbow P. Writing with Power: Techniques for Mastering the Writing Process. New York/Oxford: Oxford University Press; 1981.
27. Kugelmann R. Complaining about chronic pain. Soc Sci Med. 1999;49:16-63

28. Peolsson M, Hyden L-C, Satterlund Larsson U. Living with chronic pain: a dynamic learning process. Scand J Occup Ther. 2000;7(3):114-125.

29. Burlingame MG, Fuhriman A, Johnson JE. Cohesion in group psychotherapy. Psychotherapy. 2001;38(4):373-379.

30. Thorn BE, Kuhajda MC. Group cognitive therapy for chronic pain. J Clin Psychol. 2006;62(11):1355-1366.

31. Cassell EJ. The Nature of Suffering and the Goals of Medicine. 2nd edition. New York: Oxford University Press; 2004.

32. Holmes SE, Kivlighan DM. Comparison of therapeutic factors in group and individual treatment processes. J Couns Psychol. 2000;47(4):478-484.

33. Raleigh EDH. Hope and hopelessness. In: Rice VH, editor. Handbook of Stress, Coping and Health. London: Sage Publications; 2000:437-459.

34. Dufault K, Martocchio BC. Symposium on compassionate care and the dying experience. Hope: its spheres and dimensions. Nurs Clin North Am. 1985;20(2):379-391.

35. Dysvik E, Furnes B. Nursing leadership in a chronic pain management group approach. J Nurs Manag. 2012;20(2):187-195.

36. Brown CA, Richardson C. Nurses' in the multi-professional pain team: a study of attitudes, beliefs and treatment endorsements. Eur J Pain. 2006;10(1):13-22.

37. Dysvik E, Stephens P. Conducting rehabilitation groups for people suffering from chronic pain. Int J Nurs Pract. 2010;16(3):233-240.

38. Wells-Federman C, Arnstein P, Caudill M. Nurse-led pain management program: effect on self-efficacy, pain intensity, pain-related disability, and depressive symptoms in chronic pain patients. Pain Manag Nurs. 2002;3(4):131-140.

39. Williams ACC. Cognitive-behavioral pain management: lessons learned. In: McQuay HJ, Kalso E, Moore RA, editors. Systematic Reviews in Pain Research: Methodology Refined. Seattle: IASP Press; 2008:275-284.
Patient Preference and Adherence

\section{Publish your work in this journal}

Patient Preference and Adherence is an international, peer-reviewed, open access journal that focuses on the growing importance of patient preference and adherence throughout the therapeutic continuum. Patient satisfaction, acceptability, quality of life, compliance, persistence and their role in developing new therapeutic modalities and compounds to optimize

\section{Dovepress}

clinical outcomes for existing disease states are major areas of interest for the journal. This journal has been accepted for indexing on PubMed Central. The manuscript management system is completely online and includes a very quick and fair peer-review system, which is all easy to use. Visit http://www. dovepress.com/testimonials.php to read real quotes from published authors. 